\title{
Retroperitoneal hematoma following hysteroscopic removal of levonorgestrel intrauterine system: a case report
}

\author{
Andrea S. O'Shea, MD, ${ }^{1}$ Jennifer C. Steines, MD, ${ }^{1}$ Abbey J. Hardy-Fairbanks, MD $^{1}$
}

Keywords: Intrauterine devices, IUD, IUC, IUS, perforation, complication, uterine artery, missing strings

\begin{abstract}
Long acting reversible contraceptive (LARC) devices such as the levonorgestrel intrauterine system (LNG-IUS) have increased in use. Care should be taken with insertion and removal of the device as, although rare, serious complications can occur. We present a case of retroperitoneal hematoma following hysteroscopic removal of LNG-IUS.

${ }^{1}$ University of lowa Hospitals and Clinics, Department of Obstetrics and Gynecology, lowa City, lowa.
\end{abstract}

\section{Case Report}

Permission was obtained from the patient to have her clinical course published. A 21-year-old G1P1 healthy female with no medical problems or surgical history presented to her local gynecologist for removal/replacement of levonorgestrel intrauterine system (LNG-IUS) for contraceptive purposes. Her previous LNG-IUS was placed postpartum following an unplanned pregnancy five years prior. She had remained amenorrheic with the intrauterine system (IUS) and reported no issues. Upon exam, the physician was unable to visualize IUS strings. Inoffice attempts were made at removal using both an IUS retrieval device as well as an endometrial biopsy Pipelle. These attempts were unsuccessful. An ultrasound was not performed.

The patient was then taken to the operating room for hysteroscopic removal of the IUS. It was specifically documented that on inspection the IUS did not appear embedded into the myometrium. Documentation revealed the IUS was removed with a small curette after attempts with an IUS hook as well as polyp forceps were not successful. Approximately 4 hours postprocedure, the patient called her local provider and reported significant abdominal pain. She returned to the hospital for additional evaluation. On arrival, the patient was noted to have a syncopal event; vital signs included heart rate of 120 beats per minute,

Please cite this paper as: O'Shea AS, Steines JC, Hardy-Fairbanks AJ. Retroperitoneal hematoma following hysteroscopic removal of LNG-IUS: a case report. Proc Obstet Gynecol. 2014;4(2): Article 8 [ 3 p.]. Available from: http://ir.uiowa.edu/pog/. Free full text article.

Corresponding author: Andrea Smiens O'Shea, MD, Resident Physician, Obstetrics and Gynecology, Department of Obstetrics \& Gynecology, University of lowa Hospitals and Clinics, 200 Hawkins Drive, lowa City, IA 52242, Phone: 319-3562294, Fax: 319-384-8620. andrea-oshea@uiowa.edu

Copyright: (c) 2014 O'Shea, et al. This is an open-access article distributed under the terms of the Creative Commons Attribution License, which permits unrestricted use, distribution, and reproduction in any medium, provided the original author and source are credited. 
blood pressure of $70-80 \mathrm{~mm} \mathrm{Hg}$ systolic and $30-40 \mathrm{~mm} \mathrm{Hg}$ diastolic. She received 2 units of packed red blood cells (PRBC) and was taken to the operating room emergently.

A laparoscopy was performed with visualization of a massive, but stable, retroperitoneal hematoma with no active sites of bleeding. Her intraoperative hematocrit was $17 \%$, and she received an additional 2 units of PRBC. The surgery was concluded and the patient was admitted overnight. Her postoperative hematocrit was 19\%. Given continued post-operative pain and inappropriate rise in her hematocrit, the patient was transferred to our tertiary care center.

Upon arrival, she was taken emergently to interventional radiology. On angiogram, active bleeding was noted from the right uterine artery and the patient underwent successful right uterine artery embolization. She received 1 unit of PRBC postoperatively. The remainder of her hospital course was uncomplicated, and she was discharged on post-operative day 3 after her initial hysteroscopy. Her only post-procedure finding was a urinary tract infection. She was seen in follow up and started on oral contraceptive pills for contraceptive purposes.

\section{Comment}

Approximately $36 \%-50 \%$ of pregnancies are unintended. ${ }^{1}$ Long acting reversible contraception (LARC) devices, including the LNG-IUS, have become more favorable in recent years. According to data from the National Survey of Family Growth, the use of IUSs for contraceptive purposes has increased from $1.3 \%$ in 2002 to $5.5 \%$ in 20062008. ${ }^{2}$ The World Population Bureau reported in 2008 that the IUS was the second most popular form of contraception after female sterilization. ${ }^{3}$

There are various methods for removal of IUSs where the strings cannot be visualized. In China, many IUSs are manufactured without threads; therefore, removal is dependent upon physician experience and tactile sensation. ${ }^{4}$ Documented methods for removal of IUS with strings that are not visualized include the use of an IUS hook, curette, hysteroscopy, and, in some cases, laparoscopy or laparotomy. ${ }^{5}$ A case series previously published also suggests that misoprostol may improve the ability to remove IUSs. ${ }^{6}$

Upon review of the literature, this is the first report of uterine artery damage associated with removal of an IUS that was not embedded. There are, however, reports of lateral uterine perforation with hysteroscopy. Lateral uterine perforation can lead to retroperitoneal hematomas which have been managed by laparoscopy, laparotomy, hysterectomy, and, in more recent cases, uterine artery embolization. ${ }^{7,8} \quad$ Retroperitoneal hematomas are a rare complication of various procedures. ${ }^{9}$ Management of retroperitoneal hemorrhage remains controversial. Conservative management may be appropriate for the stable patient; however, a recent review suggests that interventional radiology with intra-arterial embolization should be the treatment of choice. However, it is imperative to continue to monitor these patients closely as some may develop abdominal compartment syndrome 
requiring a decompressing laparotomy. ${ }^{9}$

This case highlights the importance of care when removing an IUS without visible strings.

\section{References}

1. Finer LB, Zolna MR. Unintended pregnancy in the United States: incidence and disparities, 2006. Contraception. 2011 Nov;84(5):478-85. doi:

10.1016/j.contraception.2011.07.013.

Epub 2011 Aug 24. PubMed PMID: 22018121.

2. Mosher WD, Jones J. Use of contraception in the United States: 1982-2008. Vital Health Stat 23. 2010 Aug;(29):1-44. PubMed PMID: 20939159.

3. American College of Obstetricians and Gynecologists. ACOG Practice Bulletin No. 121: Long-acting reversible contraception: Implants and intrauterine devices. Obstet Gynecol. 2011 Jul;118(1):184-96. doi: 10.1097/AOG.0b013e318227f05e.

PubMed PMID: 21691183.

4. Su S, Zhao Z, Feng S, Dong B. A novel medical device for removal of intrauterine devices under direct vision. Contraception. 2012 Nov;86(5):583-6. doi:

10.1016/j.contraception.2012.04.002.

Epub 2012 May 22. PubMed PMID:22625866.
5. Yazicioglu HF, Yasar L, Dülger $O$. Hysteroscopic removal of a foreign body from the subvesical space. Int $\mathrm{J}$ Gynaecol Obstet. 2004 Jul;86(1):48-9. http://dx.doi.org/10.1016/j.ijgo.2004.04.0 31. PubMed PMID:15207676.

6. Cowman WL, Hansen JM, HardyFairbanks AJ, Stockdale CK. Vaginal misoprostol aids in difficult intrauterine contraceptive removal: a report of three cases. Contraception. 2012 Sep;86(3):281-4. doi: 10.1016/j.contraception.2012.01.007. Epub 2012 Feb 24. PubMed PMID: 22364817.

7. Jansen FW, Vredevoogd $\mathrm{CB}$, van Ulzen $\mathrm{K}$, Hermans J, Trimbos JB, TrimbosKemper TC. Complications of hysteroscopy: a prospective, multicenter study. Obstet Gynecol. 2000 Aug;96(2):266-70. http://dx.doi.org/10.1016/S00297844(00)00865-6. PubMed PMID: 10908775 .

8. Rothenberg R. Management of lateral uterine perforation at the time of hysteroscopy. Foundation for Exxcellence in Womens Healthcare [Internet]. 2012 [ cited 2014 Apr 18]. Available from: http://www.exxcellence.org/pearls.php?i $d=48$.

9. Chan YC, Morales JP, Reidy JF, Taylor PR. Management of spontaneous and iatrogenic retroperitoneal haemorrhage: conservative management, endovascular intervention or open surgery? Int J Clin Pract. 2008 Oct;62(10):1604-13. Epub 2007 Oct 19. DOI: $\quad 10.1111 /$ j.17421241.2007.01494.x. PubMed PMID: 17949429. 